\title{
Analysis of Flood Routing
}

\author{
Md. Motaleb Hossain
}

Department of Mathematics, Dhaka University, Dhaka 1000, Bangladesh

(Received: 26 May 2012; Accepted: 4 May 2014)

\begin{abstract}
Flood routing is the technique of determining the flood hydrograph at a section of a river by utilizing the data of flood flow at one or more upstream sections. The hydrologic analysis of problems such as flood forecasting, flood protection, reservoir design and spillway design invariably include flood routing. In these applications two broad categories of routing can be recognized. These are reservoir routing and channel routing. In reservoir routing the effect of a flood wave entering a reservoir is studied. In channel routing the change in the shape of a hydrograph as it travels down a channel is studied. In this paper pick rate of runoff and risk of a coffer dam for different construction years are discussed. We found that peakrate depends on length of travel of water course and risk of coffer dam is more if it is designed for short time for long construction period.
\end{abstract}

Keywords: Routing, hydrograph, forecasting, reservoir, spillway, coffer dam

\section{List of Symbols}

$\mathrm{X}$

Distance along the flow direction from some reference point to the section under consideration

Q Discharge at the section

A Area of the flow at the section

$\mathrm{V} \quad$ Average velocity of flow

y Depth of flow at section

g Acceleration due to gravity

I Intensity of rainfall

C Runoff coefficient

$t_{c} \quad$ Time of concentration

$L \quad$ Maximum length of travel of water along the water course

$S \quad$ Storage of reservoir

\section{Introduction}

The term flood routing refers to procedures to determine the outflow hydrograph at a point downstream in a river (or reservoir) as a function of the inflow hydrograph at a point upstream. As flood waves travel downstream they are attenuated and delayed. That is, the peak flow of the hydrograph decreases and the time base of the hydrograph increases. Again design flood is the flood discharge adopted for the design of a structure after careful consideration of economic and hydrologic factors. As the magnitude of the design flood increases, the capital cost of the structure also increases but the probability of annual damages will decrease.

\section{Reservoir Routing}

Let I and Q be the inflow into and outflow from a reservoir, and $S$ the storage in the reservoir, the continuity equation in the differential form for the reservoir is given by

$$
\mathrm{I}-\mathrm{Q}=\frac{\mathrm{dS}}{\mathrm{dt}}
$$

Alternatively, the same can be written as

$$
\overline{\mathrm{I}} \Delta \mathrm{t}-\overline{\mathrm{Q}} \Delta \mathrm{t}=\Delta \mathrm{S}
$$

where, $\bar{I}$ is the average inflow rate in a small time interval $\Delta t, \bar{Q}$ is the average outflow rate in the same time interval and $\Delta S$ is the corresponding change in the storage of the reservoir during the same time interval. If suffixes 1 and 2 are used to denote a given quantity at the beginning and the end of the time interval and if the inflow and outflow have straight line variation within the time interval, Eq. (2) can be written as

$$
\left(\frac{\mathrm{I}_{1}+\mathrm{I}_{2}}{2}\right) \Delta \mathrm{t}-\left(\frac{\mathrm{Q}_{1}+\mathrm{Q}_{2}}{2}\right) \Delta \mathrm{t}=\mathrm{S}_{2}-\mathrm{S}_{1}
$$

\section{Channel Routing}

The channel routing, or stream channel routing as it is called often, uses mathematical relations to calculate outflow from a stream channel once inflow, lateral contributions and channel characteristics are known. The terms channel routing and flood routing are used interchangeably. This is because most of the channel routing applications are in flood flow analysis, flood control design and flood forecasting.

The specific length of a stream channel between the upstream sections where the hydrograph is known and the downstream sections where the hydrograph is to be determined is called a channel reach. The hydrograph at the upstream end of the reach is the inflow hydrograph and the hydrograph at the downstream end of the reach is the outflow hydrograph. Lateral contributions consist of tributary inflow joining the reach at different points, and/or the contributions due to interflow and groundwater flow which may be distributed over the part or full length of the reach. When there is no lateral flow into the channel reach, the unsteady flow in the channel is described by the following two equations which are known as SaintVenant [1] equations.

$$
\begin{aligned}
& \frac{\partial \mathrm{Q}}{\partial \mathrm{x}}+\frac{\partial \mathrm{A}}{\partial \mathrm{t}}=0 \\
& \frac{\partial \mathrm{V}}{\partial \mathrm{t}}+\mathrm{V} \frac{\partial \mathrm{V}}{\partial \mathrm{x}}+\mathrm{g}\left(\frac{\partial \mathrm{y}}{\partial \mathrm{x}}-\mathrm{S}_{0}+\mathrm{S}_{\mathrm{f}}\right)=0
\end{aligned}
$$

Eq. (4) is the continuity equation which expresses the conservation of mass and Eq. (5) is the momentum equation which expresses the conservation of momentum. The solution of these two partial differential equations will provide the answer for flood routing problem. Methods of flood routing based on these equations are known as the hydraulic routing methods. Though the hydraulic routing methods are theoretically more exact, in general they 
assume a uniform channel section and therefore they become cumbersome when applied to irregular natural channels.

In contrast, the hydraulic routing method makes use of only the continuity equation. The Muskingum method is the most widely used hydrologic channel routing method which is now described.

\section{IV.MuskingumMethod}

As in the reservoir routing, in the channel routing also a second independent relationship is required to solve for $\mathrm{Q}_{2}$ and $\mathrm{S}_{2}$ in Eq. (3). This is provided by the Muskingumstorage equation which assumes that the storage in the channel reach at any time is dependent both on inflow and outflow.

The storage in the channel routing reach consists of two parts, namely, the prism storage and the wedge storage is formed by a volume of constant cross section along the length of the prismatic channel which is shown in the Fig. 1. Assuming that the cross-sectional area of the flood flow is directly proportional to the discharge at the section, the volume of prism storage is equal to $K Q$, where $K$ is a constant of proportionality, evidently possessing dimensions of time. The wedge storage may be taken as a fraction of the volume of the prism corresponding to $(I-Q)$. In the earlier stages when $>Q$, the wedge is positive and when $\mathrm{I}<\mathrm{Q}$ during later stages a negative wedge is formed. The volume of wedge storage is then equal to $\operatorname{Kx}(\mathrm{I}-\mathrm{Q})$, where $\mathrm{x}$ is a weighting factor having the range $0 \leq \mathrm{x} \leq 0.5$.

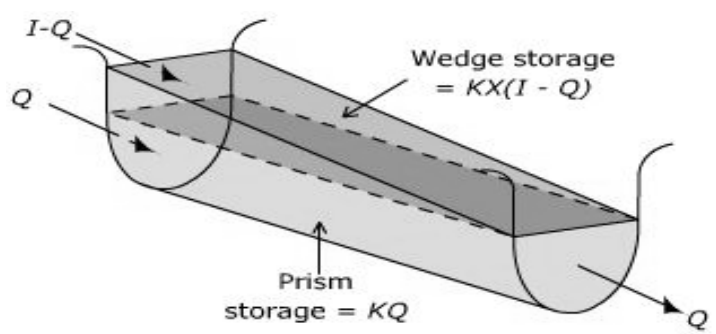

Fig. 1.Prism and wedge storages in a channel reach

The total storage is therefore equal to the sum of the two components,

$$
\mathrm{S}=\mathrm{KQ}+\mathrm{Kx}(\mathrm{I}-\mathrm{Q})
$$

which can be rearranged to give the storage function for the Muskingummethod

$$
\mathrm{S}=\mathrm{K}(\mathrm{xI}+(1-\mathrm{x}) \mathrm{Q})
$$

The value of $x$ depends on the shape of the wedge. It ranges from 0 for reservoir type storage to 0.5 for a full wedge. When $x=0$, there is no wedge and this represents the case of a level-pool reservoir. In natural streams $x$ lies between 0 and 0.3 with a mean value of around 0.2. Great accuracy in determining $\mathrm{x}$ may not be necessary because the results of the method are relatively insensitive to the value of this parameter. The parameter $\mathrm{K}$ represents the time of travel of the flood wave through the channel reach. The value of $\mathrm{K}$ depends on the length of the reach and other roughness characteristics. The values of $\mathrm{K}$ and $\mathrm{x}$ are to be determined from a pair of observed inflow and outflow hydrographs. Using Eq. (4), the change in storage is now given by

$$
\mathrm{S}_{2}-\mathrm{S}_{1}=\mathrm{K}\left[\mathrm{x}\left(\mathrm{I}_{2}-\mathrm{I}_{1}\right)+(1-\mathrm{x})\left(\mathrm{Q}_{2}-\mathrm{Q}_{1}\right)\right]
$$

Substituting Eq. (5) in Eq. (3) and rearranging the terms, we get

$$
\mathrm{Q}_{2}=\mathrm{C}_{0} \mathrm{I}_{2}+\mathrm{C}_{1} \mathrm{I}_{1}+\mathrm{C}_{2} \mathrm{Q}_{1}
$$

Where $\mathrm{C}_{0}, \mathrm{C}_{1}$ and $\mathrm{C}_{2}$ are called the routing coefficients given by

$\mathrm{C}_{0}=\frac{(\Delta \mathrm{t} / \mathrm{K})-2 \mathrm{x}}{2(1-\mathrm{x})+(\Delta \mathrm{t} / \mathrm{K})}$

$\mathrm{C}_{1}=\frac{\left(\frac{\Delta \mathrm{t}}{\mathrm{K}}\right)+2 \mathrm{x}}{2(1-\mathrm{x})+(\Delta \mathrm{t} / \mathrm{K})}$

$\mathrm{C}_{2}=\frac{2(1-\mathrm{x})-(\Delta \mathrm{t} / \mathrm{K})}{2(1-\mathrm{x})+(\Delta \mathrm{t} / \mathrm{K})}$

It may be easily verified that $C_{0}+C_{1}+C_{2}=1$ which fact can be used as an arithmetical check on the computed values of the routing coefficients. It should be noted that while computing $\mathrm{C}_{0}, \mathrm{C}_{1}$ and $\mathrm{C}_{2}$ both $\mathrm{K}$ and $\Delta \mathrm{t}$ must be in the same units of time. Given an inflow hydrograph, the initial outflow, a chosen time interval $\Delta t$, and the routing parameters $\mathrm{K}$ and $\mathrm{x}$, the routing coefficients can be calculated with Eq. (10) to Eq. (12) and the outflow hydrograph with Eq. (9).

Determining of the outflow $Q_{2}$ at the end of any time interval using Eq. (9) requires the value of $Q_{1}$ (the outflow at the end of previous time interval) which is obtained in the earlier iteration. With a small loss of accuracy in the results, the outflow can be determined using only the inflow ordinates as follows. Consider the routing equation for the third time interval

$$
\begin{gathered}
\mathrm{Q}_{4}=\mathrm{C}_{0} \mathrm{I}_{4}+\mathrm{C}_{1} \mathrm{I}_{3}+\mathrm{C}_{2} \mathrm{Q}_{3} \\
=\mathrm{C}_{0} \mathrm{I}_{4}+\mathrm{C}_{1} \mathrm{I}_{3}+\mathrm{C}_{2}\left(\mathrm{C}_{0} \mathrm{I}_{3}+\mathrm{C}_{1} \mathrm{I}_{2}+\mathrm{C}_{2} \mathrm{Q}_{2}\right) \\
+\mathrm{C}_{1} \mathrm{I}_{3}+\mathrm{C}_{2}\left[\mathrm{C}_{0} \mathrm{I}_{3}+\mathrm{C}_{1} \mathrm{I}_{2}+\right. \\
\mathrm{C}_{2}\left(\mathrm{C}_{0} \mathrm{I}_{2}+\mathrm{C}_{1} \mathrm{I}_{1}+\mathrm{C}_{2} \mathrm{Q}_{1}\right) \\
=\mathrm{C}_{0} \mathrm{I}_{4} \\
\mathrm{C}_{0} \mathrm{I}_{4}+\left(\mathrm{C}_{1}+\mathrm{C}_{2} \mathrm{C}_{0}\right) \mathrm{I}_{3}+\left(\mathrm{C}_{1} \mathrm{C}_{2}+\mathrm{C}_{2}{ }^{2} \mathrm{C}_{0}\right) \mathrm{I}_{2}+
\end{gathered}
$$
$\mathrm{C}_{2}{ }^{2} \mathrm{C}_{1} \mathrm{I}_{1}+\mathrm{C}_{2}{ }^{3} \mathrm{Q}_{1}$.

Since $\mathrm{C}_{2}$ is always less than unity, $\mathrm{C}_{2}{ }^{3}$ approaches zero if $\mathrm{C}_{2}$ is small and hence the last term in the above equations can be neglected. The routing equation can now be expressed only in terms of inflows as

$\mathrm{Q}_{\mathrm{n}}=\mathrm{C}_{0} \mathrm{I}_{\mathrm{n}}+\left(\mathrm{C}_{1}+\mathrm{C}_{2} \mathrm{C}_{0}\right) \mathrm{I}_{\mathrm{n}-1}+\left(\mathrm{C}_{1} \mathrm{C}_{2}+\mathrm{C}_{2}{ }^{2} \mathrm{C}_{0}\right) \mathrm{I}_{\mathrm{n}-2}+$

$\mathrm{C}_{2}{ }^{2} \mathrm{C}_{1} \mathrm{I}_{\mathrm{n}-3}$

with $n=4,5$, ...etc.

Barati et al. [2] determined hydrologic parameters using recorded data in bothupstream and downstream sections of rivers and/or by applying robust optimization techniqueswith the help of Muskingum models. 


\section{Derivation of out Flow Hydrograph from Inflow Hydrograph}

Consider the flood hydrograph given in the following table through a channel reach and we will derive the outflow hydrograph.

\begin{tabular}{|l|lllllllll|}
\hline Time-h & 0 & 8 & 16 & 24 & 32 & 40 & 48 & 56 & \\
\hline Flow-m $^{3}$ & 42 & 116 & 194 & 192 & 150 & 106 & 74 & 54 \\
\hline
\end{tabular}

We calculate the values for outflow hydrograph by Muskingum method. Let the values of $\mathrm{K}$ and $\mathrm{x}$ for the reach be $12 \mathrm{~h}$ and 0.278 respectively. The given inflow hydrograph and derived outflow hydrograph are plotted in the following figure.

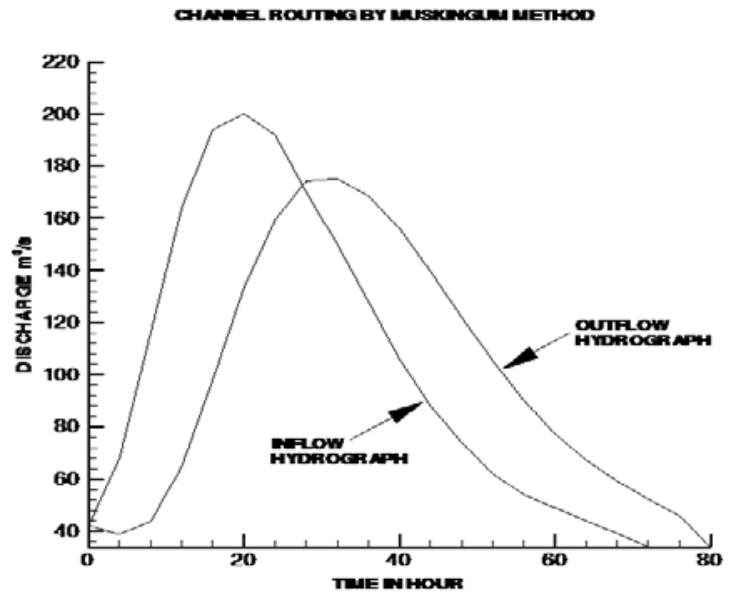

Fig. 2. Inflow and outflow hydrographs

In this above graph we see that unlike the reservoir routing, the peak flow of the outflow hydrograph in channel routing does not occur at the time where inflow and outflow hydrographs intersect.

\section{Design Flood}

Flood is the unusual high stage of a river due to runoff from rainfall and or melting of snow in quantities too great to be confined in the normal water surface elevations of the river or stream, as the result of unusual meteorological combination. The maximum flood that any structure can safely pass is called the 'Design flood' and is selected after consideration of economic and hydrologic factors. The design flood is related to the project feature and may be arrived by considering the cost of constructing the structure to provide flood control and the flood control benefits arising directly by prevention of damage to structures downstream, disruption communication, loss of life and property, damage to crops and under-utilization of land. The design flood is usually selected after making a cost-benefit analysis and exercising engineering judgment. In general the methods used in the estimation of the design flood can be grouped as below. (i) Increasing the observed maximum flood by a certain percentage

(iì) Envelope curves

(iì) Empirical flood formulae

(iv) Rational method

(v) Unit hydrograph application

(vì) Frequency analysis (or Statistical methods)

\section{Rational Method}

In this method it is assumed that the maximum flood flow is produced by a certain rainfall intensity which lasts for a time equal to or greater than the period of concentration time. This concentration time is nothing but the required for the surface runoff from the remotest part of the catchment area to reach the basin outlet. When a storm continues beyond concentration time every part of the catchment would be contributing to the runoff at outlet and therefore it represents condition of peak runoff. The runoff rate corresponding to this condition is given by

$Q=C A I$

In Eq. (14), if A and I are substituted in units of acres and inches/h, the runoff is obtained in $\mathrm{ft}^{3} / \mathrm{s}$ without requiring any conversation factor. For this reason Eq. (14) is called the rational formula.When $\mathrm{A}$ is in $\mathrm{km}^{2}$ and $\mathrm{I}$ is in $\mathrm{cm} / \mathrm{h}$, the flow rate is given by

$Q=2.778 C A I$

The maximum rainfall intensity depends on duration and frequency .The intensity of rainfall used in Eq. (15) should therefore be corresponding to duration equal to concentration time and desired return period. This requires an estimate of concentration time which is usually provided by an empirical equation given by

$t_{c}=0.0195 L^{0.77} S^{-0.385}$

Consider a problem which estimates the peak rate of runoff for a 25 year frequency

A small watershed consists of $1.5 \mathrm{~km}^{2}$ of cultivated area $(C=0.2), 2.5 \mathrm{~km}^{2} \quad$ under forest $(C=0.1)$ and $1 \mathrm{~km}^{2}$ under grass cover $(C=0.35)$. There is a fall of $22 \mathrm{~m}$ in a watercourse length of $1.8 \mathrm{~km}$. The intensity-frequency-duration relation for the area may be taken as

$I=\frac{80 T_{r}^{0.2}}{(t+13)^{0.46}}$

where I is in $c m / h, T_{r}$ is in years and tis in minutes. 


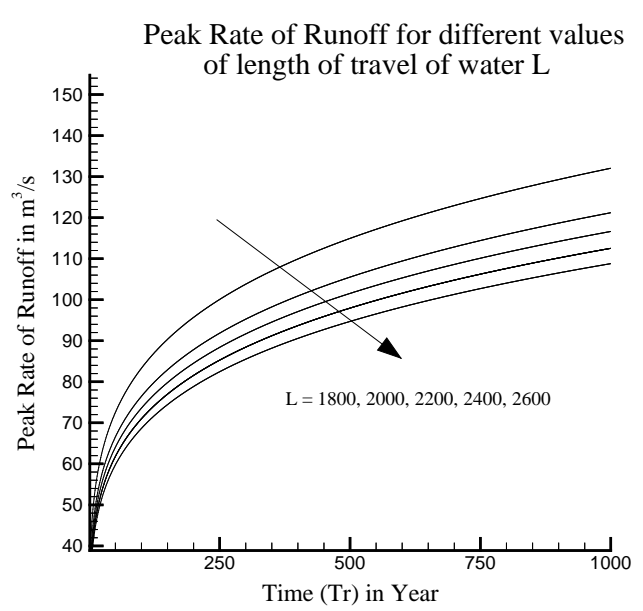

Fig. 3. The peak rate of runoff for 100 year frequency

From Fig.3 we see, at 250 years frequency the magnitude of the peak rate of runoff is $100 \mathrm{~m}^{3} / \mathrm{s}$ where the length of water course $L=1800$. If the length of water course is increased then the peak rate of runoff is decreased. We can estimate the magnitude of peak rate of runoff at any year for different values of $\mathrm{L}$.

\section{Frequency Analysis}

Frequency analysis makes use of the observed data in the past to predict the future flood events along with their probabilities or return periods. It is based on the assumption that combination of the numerous factors which produce floods are a matter of pure chance and therefore are subject to analysis according to the mathematical theory of probability.

\section{Gumbel's Distribution}

This is one of the most widely employed distributions to describe the flood data. As per this distribution the exceedence probability is given by

$$
P=1-e^{-e^{-y}}=\frac{1}{T_{r}}
$$

where, $\mathrm{y}$ is called the reduced variation given by

$y=a\left(x-x_{f}\right)$

where a and $x_{f}$ are the parameters of the distribution which can be obtained from sample statistics through the method of moments. When the sample size is large, sayn $>200$, they are given by

$a=\frac{1.28255}{S_{x}}$

$x_{f}=\bar{x}-0.45005 s_{x}$

where $\bar{x}$ and $s_{x}$ are the mean and standard deviation. However, for small samples the parameters a and $x_{f}$ are to be estimated using the following equations given by Gumbel [3].

$a=\frac{\sigma_{n}}{S_{x}} x_{f}=\bar{x}-\frac{\bar{y}_{n}}{\sigma_{n}} S_{n}$
In which $\sigma_{n}$ and $\bar{y}_{n}$ are called the standard deviation and mean of the reduced extremes which depends on the sample size $n$.

Let $y_{T}$ be the reduced variation corresponding to a return period of $T_{r}$ then from Eq. (16), we have $e^{-e^{y_{T}}}=1-P=\frac{T_{r}-1}{T_{r}}$

Taking twicelogarithms on both sideswe get

$$
\begin{gathered}
y_{T}=-\ln \left[-\ln \left(\frac{T_{r}-1}{T_{r}}\right)\right] \\
\Rightarrow>y_{T}=-\ln \left[\ln \left(\frac{T_{r}}{T_{r}-1}\right)\right]
\end{gathered}
$$

Alternatively, converting the logarithm to the base 10 , we can write

$$
y_{T}=-\left[0.834+2.303 \log \log \left(\frac{T_{r}}{T_{r}-1}\right)\right]
$$

Let $x_{T}$ denote the magnitude of the flood with a return period of $T_{r}$ years, then from Eq. (17) we get

$$
y_{T}=a\left(x_{T}-x_{f}\right)
$$

Substituting this value and simplifying, we obtain

$x_{T}=\bar{x}+\left(\frac{y_{T}-\bar{y}_{n}}{\sigma_{n}}\right) \cdot s_{x}=>x_{T}=\bar{x}+K_{T} \cdot s_{x}$

where $K_{T}$ is known as the frequency factor given by

$$
K_{T}=\left(\frac{y_{T}-\bar{y}_{n}}{\sigma_{n}}\right)
$$

It has been shown by Ven Te Chow [4]that the most frequency distribution functions applicable in hydrologic studies can be expressed by Eq. (23).Obviously the frequency factor $\mathrm{K}_{\mathrm{t}}$ depends on the type of distribution and return period.

Consider the annual flood peaks of a stream for a period of 40 years from 1941 to 1980 in $\mathrm{m}^{3}$ /s are given below.

277, 363, 496, 631, 785, 200, 809, 286, 381, 516, 653, 212, 834, 299, 400, 537, 674, 225, 857, 418, 558, 696, 238, 879, 313, 437, 577, 718, 250, 905, 328, 455, 588, 741, 263, 930, 345, 475, 609, 763.

Assuming that Gumbel [2] distribution fits the given data of estimates the 1 to 100 year flood.

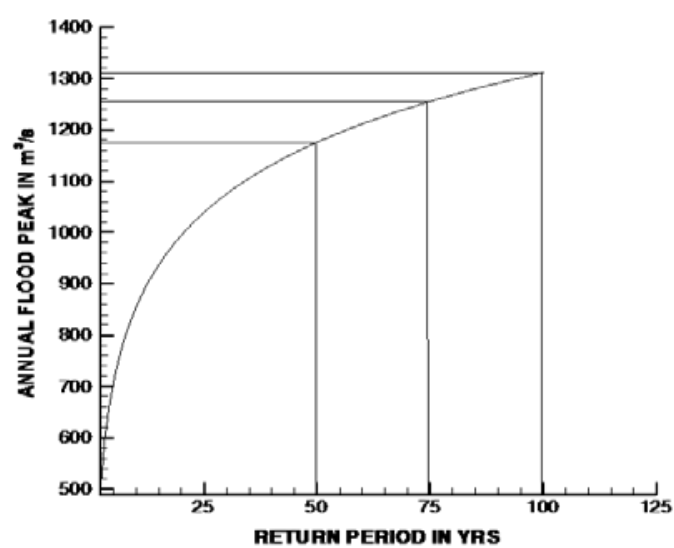

Fig. 4. Ordinary probability plot of 100 year flood. 
From Fig. 4 we see at time 100 years the magnitude of flood is approximately $1311 \mathrm{~m}^{3} / \mathrm{s}$. We can estimate any flood magnitude at any year from this graph.

\section{Selection of Design Return Period}

The return period established by frequency analysis described so far indicates only the average interval between the occurrence of floods equal to or greater than a given magnitude. There is no implication for a $T_{r}$ year flood to occur at the end of every $T_{r}$ year period. In the terminology of probability theory, $1 / T_{r}$ indicates the probability with which the $T_{r}$ year flood may be equaled or exceeded in any one year. Therefore if it is described to select a design flood which is not likely to occur during the life period of the structure, it becomes necessary to use a return period greater than the estimated useful life.Suppose that a structure is designed for $T_{T}$ year flood and its useful life period is $N$ years. Then the probability that the design flood is equaled or exceeded in any years is $1 / T_{r}$. Alternatively that the annual flood peaks are independent events, the probability that the structure does not failin the next years is $\left(1-\frac{1}{T_{Y}}\right)$.

Assuming that the annual flood peaks are independent events, the probability that the structure does not fail in the

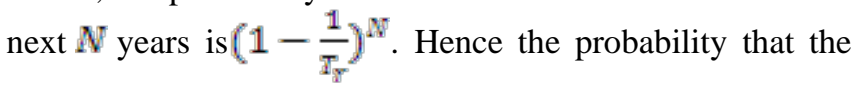
structure may fail in any one of the next $N$ years, which is nothing but the risk in the design, is given by

$$
R=1-\left(1-\frac{1}{T_{Y}}\right)^{N}
$$

The above equation may be used to evaluate the risk involved in adopting $T_{r}$ year flood for a project with useful life of $N$ years. Alternatively it can also be used to determine the required return period of the design flood for a given risk $R$ and given life period $N$. For example acoffer dam is designed for a 300 year flood and constructed. If it takes different years $\mathrm{N}$ to complete the construction of main dam, then the risk that the coffer dam may fail before the end of the construction period which is shown in the following Fig.5.

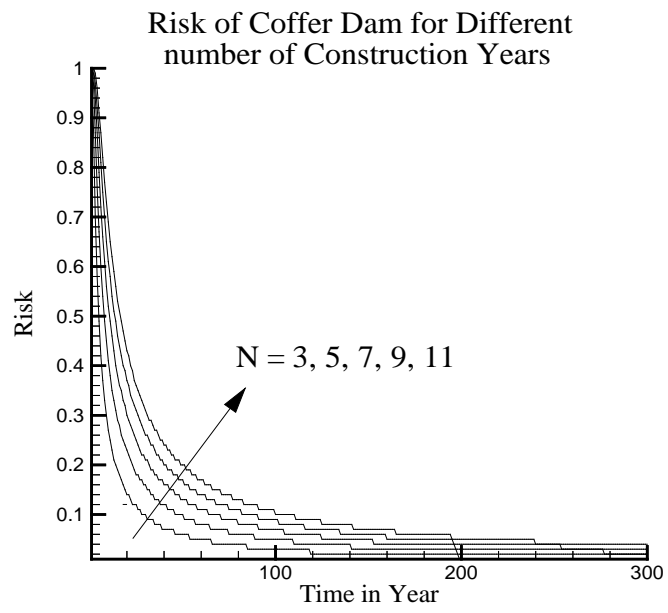

Fig. 5.Risk of Dam

From the above Fig. 5 we have observed that in $\mathrm{N}=5$ and it is designed for 50 years then the risk of failure is $10 \%$ and if the values of the construction period $\mathrm{N}$ are increased then the values of risk are increased. So in this case $\mathrm{N}$ is very sensitive.

\section{Conclusions}

In this paper, our main work is to discuss about the analysis of flood hydrograph. Hydrograph represents the graphical representation of discharge or peak flow. Flood routing and design flood are discussed. We have found that it is very important for flood forecasting and flood warning system. Analysis of flood routing and flood design is important part of hydrology. From Fig. 3, it is seen that peak run off is increased if the length of travel of water is decreased and Fig. 5 shows that if the value of $\mathrm{N}$ is increased risk of dam is also increased.

\section{References}

1. Saint Venant, 1971. Finite Element Solution of St Venant Equations 102

2. Reza BARATI, Sajjad RAHIMI, Gholam Hossein AKBARI, 2011. Analysis of dynamic wave model for flood routing innatural rivers. Water Science and Engineering 5(3): 243-258

3. Gumbel ,2003. Journal of hydrology,Mumber 1-Elsevier, Amstterdam280

4. Ven Te Chow, 1964.Handbook of Applied Hydrology, McGraw-Hill Company, New York.

5. P. Jayarami Reddi, 1994.AText book of Hydrology, Laxmi Pulications $(P)$ Ltd. New Delhi, 441-505 